\title{
Autosomal Recessive Torsion Dystonia 2
}

National Cancer Institute

\section{Source}

National Cancer Institute. Autosomal Recessive Torsion Dystonia 2. NCI Thesaurus.

Code C123415.

An autosomal recessive inherited disorder caused by mutation in the HPCA gene. It begins in childhood or adolescence and is characterized by involuntary, sustained muscle contractions and torsions affecting initially distal limbs and later the neck, orofacial, and craniocervical regions. 